\title{
A DINÂMICA DO ESPAÇO URBANO - UM ESTUDO SOBRE O BAIRRO JARDIM DAS ROSAS, PRESIDENTE PRUDENTE - SP
}

Bruno Oliveira Lopes, Daniele Regina Bosisio da Silva, Flórian Gonçalves Alonso Merique, Gabriel Morais Bianchini, Thiago Yugo Nagai Matsutane, Yeda Ruiz Maria

Universidade do Oeste Paulista - UNOESTE, Curso de Arquitetura e Urbanismo, Presidente Prudente, SP. E-mail: yeda@unoeste.br

\section{RESUMO}

O espaço urbano é composto de fragmentos, estes se encontram articulados por fluxos de diversas naturezas: de pessoas, de informações, de capitais, de mercadorias, de ideologias etc. A identidade territorial é entendida como resultado das relações sociais de um grupo em um determinado espaço ao longo de um tempo. Um bairro só é bom sendo ele claro, com características únicas e facilmente identificável interiormente pelo observador. $\mathrm{O}$ espaço urbano produz linguagens e significados e renova-os constantemente, entretanto passagem do tempo é capaz de calcificar diversos elementos culturais, produzidos em diferentes épocas, num mesmo espaço urbano. 0 presente artigo tem como objetivo analisar o território que delimita administrativamente o Bairro Jardim das Rosas, Presidente Prudente - SP, afim de entender a relação existente entre sua história de formação, a identidade social apresentada e sua cristalização em alguns pontos em específico. Para tanto faz-se necessário pesquisa bibliográfica, levantamento fotográfico in loco e observação do espaço.

Palavras-chave: Herança Territorial; Cristalização; Dinâmica urbana; Jardim das Rosas; Presidente Prudente - SP.

\section{THE DYNAMICS OF URBAN SPACE - A STUDY ABOUT THE NEIGHBORHOOD JARDIM DAS ROSAS, PRESIDENTE PRUDENTE - SP}

\begin{abstract}
The urban space is composite of fragments, they are articulated by flows of various natures: of people, informations, capital, goods, ideology and others. Territorial identity is understood as the result of the social relations of a group in a determined space with the passage of time. A neighborhood is only good if it's clear, with unique features and easily identifiable within the observer. The urban space produces languages and meanings and renews them constantly, though the passage of time is able of calcify various cultural elements, produced in different time in the same urban space. This article have the objective of analyze the territory administratively defined of the Jardim das Rosas neighborhood, Presidente Prudente - SP, in order of understand its training history, the social identity presented and its crystallization in some specific points. Also it is necessary literature, photographic survey on the ground and space observation.
\end{abstract}

Keywords: Territorial heritage; History; Crystallization; Urban Dynamics; Jardim das Rosas. 


\section{INTRODUÇÃO}

O espaço urbano se dinamiza por ações sociais, as quais definem as identidades sociais que podem ser entendidas como identidades territoriais ou heranças territoriais. Haesbaert (2007) pontua que as identidades se identificam com um espaço simbólico, sendo esse social historicamente construído, ou seja, o espaço é uma referência para a construção das identidades.

Neste sentido, a identidade territorial é entendida como resultado das relações sociais de um grupo em um determinado espaço ao longo de um tempo. Possibilita portanto que se compreenda não apenas as relações sociais do grupo estudado, mas também a noção de pertencimento a um território (HAESBAERT, 2007).

Souza (2006) esclarece que o território é uma área onde quem produz possui vínculos históricos e indenitários relacionados com o espaço físico ocupado, ou seja, é uma dada porção do espaço geográfico onde se dão todas as relações sociais, econômicas, culturais, políticas e ambientais de um grupo, necessárias à sua reprodução social em um tempo determinado.

Neste contexto o presente artigo tem como objetivo analisar o território que delimita administrativamente o Bairro Jardim das Rosas, Presidente Prudente - SP, afim de entender a relação existente entre sua história de formação, a identidade social apresentada e sua cristalização em alguns pontos em específico. Para tanto faz-se necessário pesquisa bibliográfica, levantamento fotográfico in loco e observação do espaço.

\section{A HERANÇA TERRITORIAL DO BAIRRO JARDIM DAS ROSAS}

O Bairro Jardim das Rosas, estudo de caso deste artigo, inicia sua história documentada na década de 1930, quando ainda era uma fazenda não loteada (KOLSDORF, 1999).

Havia em suas proximidades, segundo Kolsdorf (1999), algumas estradas que permitiam o fluxo dos transportes de animais até o ponto de pouso (denominação dada pela fartura de pasto para os animais e da facilidade de obtenção de água) localizado mais adiante do Matadouro Municipal (local de armazenamento de carne bovina). No ano de 1975 o matadouro tornou-se o Museu e Arquivo Histórico Prefeito Antônio Salomão Neto, após uma doação da Prefeitura Municipal (KOSDORF, 1999).

Consta na web site oficial da Prefeitura Municipal que na década de 1980 a arquiteta lara Valim projetou a atual Praça dos Imigrantes do Jardim das Rosas, sendo uma homenagem aos imigrantes japoneses, os quais contribuíram com o desenvolvimento sócio - econômico da cidade. 
Para Lynch (1960) um bairro só é bom sendo ele claro, com características únicas e facilmente identificável interiormente pelo observador. Neste sentido a densa arborização do Jardim das Rosas traz ao bairro uma identidade única.

Portanto é percebido que o Jardim das Rosas tem o Museu, o Prudenshopping, o Sesc Thermas a Unesp, a Praça dos Imigrantes e sua arborização como pontos e/ou espaços referenciais para a população, sendo eles inseridos no limite administrativo ou subjetivo do bairro (fig. 01).

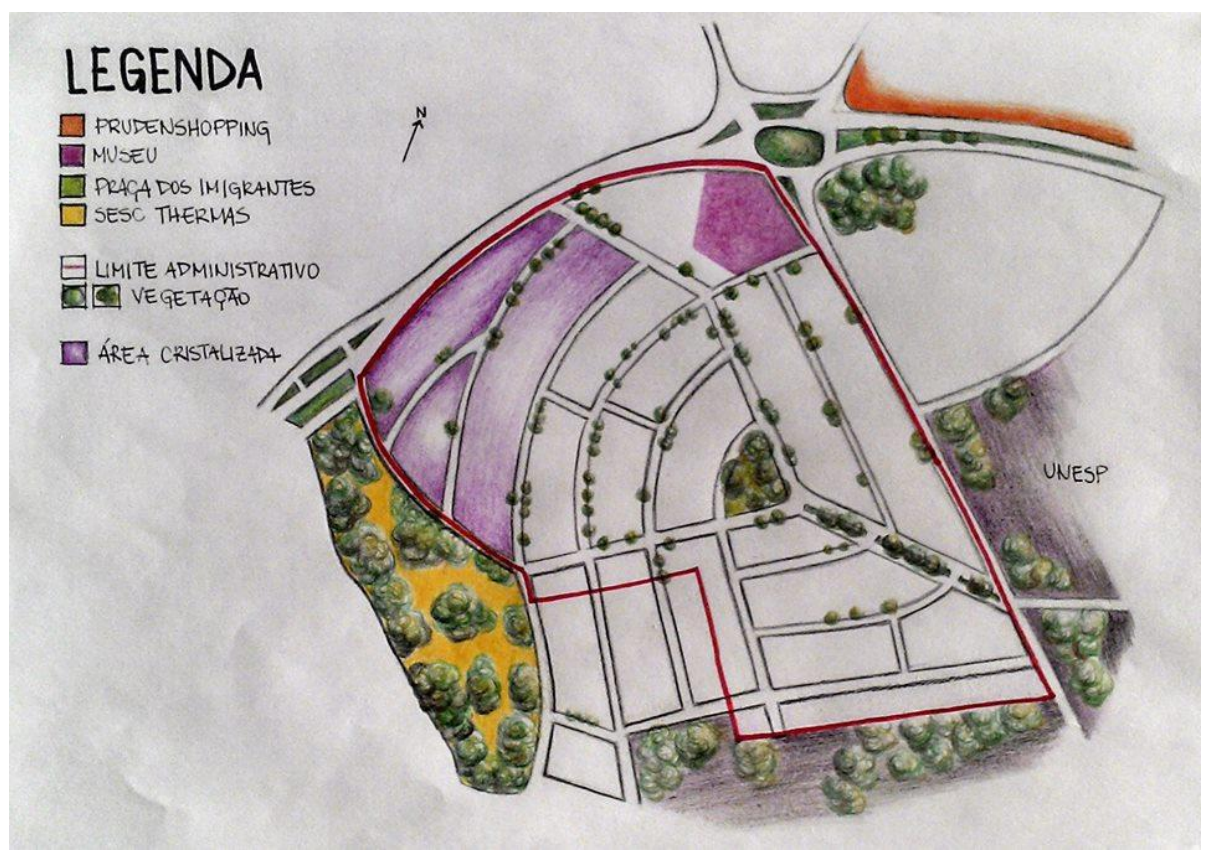

Figura 01. Pontos e/ou espaços de referência - croqui sem escala

Fonte: Autores, 2015.

Herança territorial é tudo aquilo que não conseguiu se atualizar com a modernização que a sociedade sofreu e ficou ultrapassada no tempo, perdendo seu valor e caindo no desuso, podendo ser no âmbito social, econômico, físico-territorial e cultural. Porém, com o passar o tempo e o crescimento urbano ativo, essa herança é utilizada a favor do local no qual ela está inserida, podendo manter as mesmas características antigas ou ainda inovando-a (CALIXTO, D.L; NASCIMENTO, D.N; SILVA, C.H.R; LEAL, G.Q; 2010). No caso do bairro em estudo, a herança territorial presente é o museu - antigo matadouro - que perdeu seu antigo uso (econômico) e ganhou uma nova função (cultural), no qual ainda gerou o princípio de crescimento do bairro, que se desenvolveu a partir da proximidade com o museu. Visto que é uma parcela do bairro com uma identidade mais antiga, quanto mais afastado do museu o bairro é, mais recente se encontram suas edificações. 
Os outros pontos de referências como o Prudenshopping, Sesc Thermas e a Praça dos Imigrantes, não se caracterizam como herança territorial porque já foram implantadas com a atual finalidade que apresentam nos dias de hoje, e não foram abandonadas ou caíram no desuso perdendo sua função. Todas permanecem ativas e atendendo um público de usuários que vão para desfrutar de suas respectivas atividades.

\section{A CRISTALIZAÇÂO DO ESPAÇO SEGREGANDO SOCIALMENTE}

A cidade fala de si própria pela cristalização de elementos da sua história em vários espaços. Para Sutil (2003) o espaço urbano produz linguagens e significados e renova-os constantemente, entretanto passagem do tempo é capaz de calcificar diversos elementos culturais, produzidos em diferentes épocas, num mesmo espaço urbano.

Para Côrrea (1995) esse processo natural de inércia atua, na organização espacial intraurbana, através da permanência de certos usos e certos locais, apesar de terem cessado as causas que no passado justificaram a localização deles. Entretanto gostos, convivências pessoais, interesses vocacionais e econômicos tendem a segregar, classificando socialmente as populações por espaços cristalizados (PARK apud BUENO, 2001).

Neste contexto o Jardim das Rosas apresenta o processo de cristalização na área mais antiga do bairro (próximo à Avenida Manoel Goulart e ao Sesc Thermas), sendo que esta a mercê da falta de infraestrutura e de uma arquitetura 'esquecida no tempo' (fig. 02).

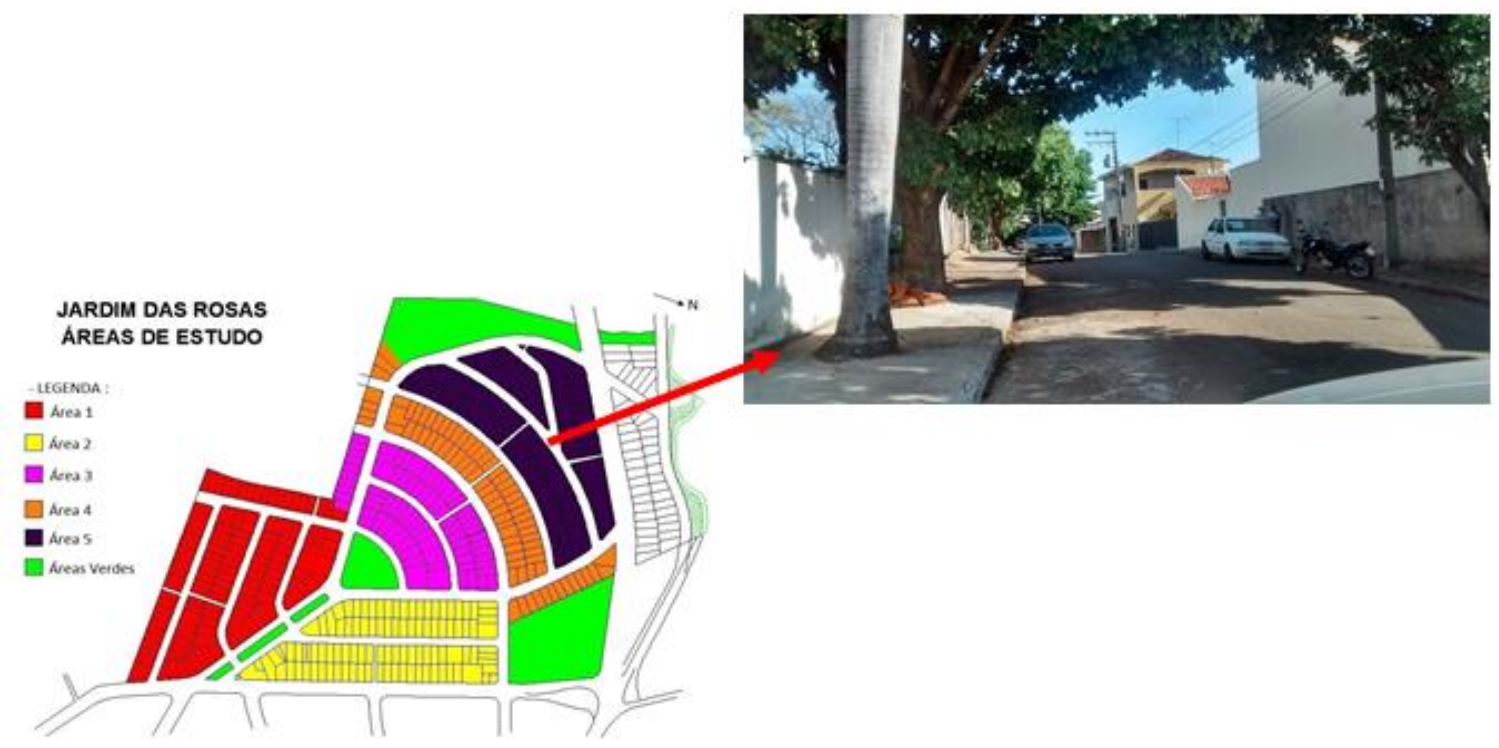

Figura 02. Área cristalizada do bairro

Fonte: autores, 2015 
Em contrapartida a área mais nova do bairro (próximo à Unesp e a Praça dos Imigrantes) tem recebido grande atenção do mercado imobiliário, propiciando para uma área mais dinâmica e vivenciada.

\section{A DINÂMICA DO ESPAÇO URBANO}

A cidade, assim como seus bairros, é produto histórico e social (SOUZA, 1988; CORRÊA, 1989; CARLOS, 2001). Segundo Corrêa (1989), o espaço urbano é composto de fragmentos, estes se encontram articulados por fluxos de diversas naturezas: de pessoas, de informações, de capitais, de mercadorias, de ideologias etc.

Essa articulação no interior do espaço urbano se dá entre os diferentes usos do solo que definem áreas como o centro da cidade, local de concentração de atividades comerciais, de serviços e de gestão, áreas industriais, áreas residenciais distintas em termos de forma e conteúdo social, de lazer, entre outras, aquelas de reserva para futura expansão (CORRÊA, 1989).

Se entende portanto que a dinâmica urbana é consequência direta do capitalismo atual, este revelado no bairro de estudo (especialmente em sua área mais nova, a não cristalizada) com a existência de instituições de lazer, educacional e cultural (Sesc Thermas, Prudenshopping, Unesp, Senai, Senac, Colégio Adventista, Espaço Cultural Timochenco Wehbi), os quais estimulam ainda mais esse processo dinâmico, já que elas favorecem um maior fluxo nos períodos de funcionamento e na instalação de residências para moradia estudantil.

\section{CONCLUSÃO}

Com o passar dos anos as cidades são formadas e fragmentos de memória urbana são deixados para trás, muitos deles acabam adquirindo um valor histórico no perfil atual da cidade, caracterizando a herança territorial.

O bairro Jardim das Rosas se desenvolveu a partir do museu, que foi uma herança territorial deixada pela cidade. Em 1980 foi o ápice do desenvolvimento do bairro e todo esse processo caracterizou o dinamismo urbano que o bairro sofre hoje.

A área mais antiga ficou estagnada no tempo e é entendida aqui como uma área cristalizada e carente. A área mais nova que acompanhou o dinamismo urbano oferece características mais amenas com relação a infra estrutura. As existências dessas duas áreas distintas segregam as características urbanas e sociais. 
O incentivo econômico, social e estrutural seria uma possibilidade dessas áreas se interagirem, fazendo de ambas heranças territoriais positivas, reconhecidas pelo mercado imobiliário e por toda a população prudentina.

\section{REFERENCIAS}

BUENO, E. de P. A Segregação Sócio-Espacial: A (Re) Produção de Espaços em Catalão - GO.

(Dissertação de Mestrado). Rio Claro: DGE/UNESP, 2001.

CALIXTO, D.N.; NASCIMENTO, D.N. do; SILVA, C.H.R. da; LEAL, G.Q. Cristalização e nodosidade: uma análise introdutória sobre a forma e a função do bairro Santa Luzia em Três Lagoa/MS. In: Anais do XVI Encontro Nacional de Geográfos - Cris, práxis e autonomia: espaços de resistência e de esperanças, espaços de diálogos e práticas. Porto Alegre: AGB. 2010

CARLOS, Ana Fani A. A Cidade. 6a Edição. São Paulo: Editora Contexto, 2001.

CARLOS, A. F. A. São Paulo: Dinâmica urbana e metropolização. In: Revista Território - Rio de Janeiro - Ano VII - no 11, 12 e 13 - set./out., 2003. Disponível em: $<$ http://www.revistaterritorio.com.br/pdf/11 12136 sao paulo.pdf > Acesso e, 10 de julho de 2015.

CORRÊA, Roberto Lobato. O espaço urbano. São Paulo: Editora Ática S.A., 1989.

HAESBAERT, R. Identidades territoriais: entre a multiterritorialidade ea reclusão territorial (ou: do hibridismo cultural à essencialização das identidades). In: ARAUJO, F. G. B. de; HAESBAERT, R. (orgs.). Identidade e territórios : questões e olhares contemporâneos. Rio de Janeiro: Acess, 2007.

KOHLSDORF \& NUNES Sociologia do espaço social de Brasília: o descontrole planejado. Brasília: Projeto integrado de pesquisa, Cnpq. 1999.

LYNCH, K. A imagem da cidade tradução Jefferson Luiz Camargo.-2ำ ed.-São Paulo: Editora WMF Martins Fontes, 2010.

NEGRI, M.N. Segregação Sócio-Espacial: Alguns Conceitos e Análises. Disponível em: <http://periodicoscientificos.ufmt.br/ojs/index.php/coletaneas/article/view/108/99> Acesso em 12 de julho de 2015.

PREFEITURA MUNICIPAL DE PRESIDENTE PRUDENTE. Inauguração da revitalização da praça do Jardim das Rosas enaltece imigrantes. Disponível em: <http://www.presidenteprudente.sp.gov.br/site/noticias.xhtml;jsessionid=A5C468A62BA43012D2 85C2DCAC136D42?cod=9932> Acesso em 10 de Julho de 2015.

SOUZA, M. A. de. Governo Urbano. São Paulo: Nobel, 1988.

SOUZA, M.L. de. O território: Sobre espaço e poder, autonomia e desenvolvimento. In: CASTRO, I.E. de. GOMES, P.C.da C; CORREA, R.L. (org.) Geografia: Conceitos e temas. 8 ed. Rio de Janeiro: Bertrand Brasil, 2006. 
SUTIL, M. S. Beirais e platibandas: a arquitetura de Curitiba na primeira metade do século XX. Curitiba: UFPR (Tese de Doutorado), 2003 